\title{
Perceptions of Help-Seeking Barriers Among College Students With Mental Health Disabilities
}

\author{
Lindsey Fullmer ${ }^{1}$, Allison R. Fleming ${ }^{2}$ b Kathleen M. Green $^{1 \mathrm{c}}$ \\ 1 Springfield College, 2 Pennsylvania State University \\ Keywords: college students, mental health, help-seeking, campus counseling center, campus disability support \\ https://doi.org/10.52017/001c.24870
}

\section{Rehabilitation Counselors and Educators Journal}

Vol. 10, Issue 1, 2021

\begin{abstract}
Colleges and universities are seeing increasing numbers of students seeking mental health services, including both students who have a history of mental health conditions and those seeking support for the first time. The academic consequences for students with mental health conditions are significant, including poor class attendance, lower grade-point average, and course failure. Individuals struggling academically are less likely to persist and graduate with a degree. Understanding student experiences, including their satisfaction with mental health services, is critical to providing effective resources.

Perceptions of stigma, campus climate, and satisfaction with services are among the most prevalent barriers to help-seeking, presenting significant challenges to efforts to support student mental health. This study used data from the Healthy Minds questionnaire to examine differences in perceptions of help-seeking barriers based on students' history of mental health diagnoses and indicators of self-harm. Results indicated students with histories of mental health and/or risk of self-harm have fewer positive perceptions of stigma, campus climate, and satisfaction with services on campus. Suggestions for professionals providing supports to college students with mental health disabilities are provided.
\end{abstract}

Enrollment rates among students with mental health disabilities in higher education have continued to increase in recent years (National Council on Disability, 2017). It is estimated that $40 \%$ of undergraduate students have a mental health condition (Campbell \& Wescott, 2019). For some students, the transition to college may trigger the first onset of mental health issues, while those with mental health histories may experience exacerbated symptoms (Pedrelli et al., 2015). Earlier research has shown the impact of mental health conditions on young people is greater than any other health-related issue, with the potential for significant negative impacts on their academic success, employment, and economic self-sufficiency (Eisenberg et al., 2009). According to the Center for Collegiate Mental Health $(\mathrm{CCMH}$; 2021), campus counseling centers have experienced a significant increase in service utilization over the last 20 years. Depression and anxiety continue to be the most prevalent presenting concerns assessed by clinicians, with trends also showing a need for more short-term crisis support instead of traditional treatment.

Based on a survey of directors for campus counseling centers, Gallagher (2014) reported 94\% of directors indicated an increase in the number of student crises that re- quire immediate responses. This includes students presenting with higher distress index scores and seeking help for suicidal ideation, attempts, and self-harm (Xiao et al., 2017). Reetz and colleagues' (2016) annual survey for the Association for University and College Counseling Center Directors (AUCCD) reported 21\% of college students seek services due to suicidal ideation, and $16 \%$ of college students have received extensive mental health treatment prior to college. Further, the COVID-19 pandemic has exacerbated mental health concerns amongst college administrators and students. The American Council on Education's survey on institutional responses to the COVID-19 pandemic reported student mental health as the top concern for college and university presidents (Turk et al., 2020). College students report lower levels of psychological wellbeing since the pandemic and that their mental health has negatively impacted academic performance (Martinez \& Nguyen, 2020). The potential academic consequences of mental health conditions are substantial, as college students with mental health conditions are twice as likely to drop out (Hartley, 2010). "Students with a mental health condition also have the poorest rates of school attendance, lowest grade-point averages (GPAs), and highest course

\footnotetext{
a Ifullmer@springfieldcollege.edu

b apf5208@psu.edu

c kgreen5@springfieldcollege.edu
} 
failure and expulsion/suspension rates of any students with disabilities" (Ringelsen et al., 2015, p. 1).

Students registered for disability services may qualify for reasonable accommodations in the classroom, which can include extended exam time, alternative assignments, and/ or academic coaching (Maxwell, 2014). However, the challenge is many students with mental health conditions do not register for services with student disability resource (SDR) offices (O’Shea \& Kaplan, 2018), despite evidence that early access to accommodations can improve academic outcomes for students with disabilities (Lightner et al., 2012). According to the National Council on Disability (2017), some barriers to service access include perceived stigma, concerns for confidentiality, and lack of knowledge regarding the availability of accommodations. Traditional academic accommodations alone may not meet the needs of students with mental health conditions. As Hartrey et al. (2017) note, colleges and universities have largely focused student accommodations on examinations; however, this does not consider the impact that mental health symptoms have on other academic and personal concerns. As such, SDR offices have the potential to build partnerships with campus offices, including counseling centers, to address these barriers and serve as a critical resource for students with mental health conditions.

\section{Campus Response to Mental Health}

The growing concern for students with mental health conditions is challenging for campus counseling centers given additional resources are necessary to meet the intense needs of this population (Xiao et al., 2017). Many centers are severely overburdened and underresourced, seeing five-year gains in utilization of 30-40\%, even while enrollment has only increased about 5\% (Center for Collegiate Mental Health, 2019). Moreover, students are increasingly seeking services for severe mental health crises. Some campus counseling centers must enforce resource limits due to high volume and insufficient abilities to treat, causing many students to be referred to community counselors (Gallagher, 2014). Greater attention from student affairs professionals has been given to address the increased need for support. For instance, some have turned to studentrun organizations in efforts to raise awareness of stigma surrounding mental health and help-seeking (Michaels et al., 2015; Walther et al., 2014), while others have implemented mental health educational programs (Yamaguchi et al., 2011).

Students have also reported the usefulness of emotional/ social support they receive at SDR, although not an explicit service provided by disability offices (Abreu et al., 2016). SDR offices, which have been underutilized by students with mental health conditions (O’Shea \& Kaplan, 2018), stand to provide important support on college campuses, particularly if they have a master's-level trained rehabilitation counselor on staff. Rehabilitation counselors bring knowledge of counseling, including mental health counseling, as well as rehabilitation knowledge consisting of the medical, functional, and psychosocial aspects of mental health disabilities (Leahy et al., 2008). They are also knowledgeable of rehabilitation services and resources, and pro- fessional advocacy skills.

Campus climate issues surrounding mental health have also been addressed to increase support to students experiencing challenges to their mental wellness, such as implementing gatekeeper training for faculty and staff to help students access proper treatment (Collins \& Mowbray, 2005; Gallagher, 2014; Schwartz, 2017; Tompkins \& Witt, 2009). SDR offices have presented on topics of mental health and service availability at new student orientation (Collins \& Mowbray, 2005). Campus counseling centers have also transitioned their approach to improve services for students, such as increasing the number of staff available to handle student concerns (Gallagher, 2014) and adjusting waitlist and referral processes (Murphy \& Martin, 2004). Despite increased response to college student mental health service needs, barriers to help-seeking remain prevalent. Prior research has examined several key areas impacting help-seeking among college students, including perceptions of stigma, campus climate, and satisfaction with services.

\section{Barriers to Help-Seeking}

Stigma is frequently referenced as a barrier to accessing mental health treatment (Corrigan, 2004; Vogel et al., 2009). Stigma has also been identified as a barrier to disclosure, help-seeking, and support for college students with mental health disabilities, which is concerning given students report academic accommodations as most useful (Hartrey et al., 2017). Research demonstrates mental health stigma is a causal factor for not obtaining mental health treatment and/or dropping out of treatment prematurely. The National Comorbidity Survey (NCS) found 9.1\% of individuals did not obtain mental health treatment due to perceived stigma (Mojtabai et al., 2011). Moreover, 21.2\% of individuals reported dropping out of treatment due to perceived stigma. The assumption that traditional collegeage students are particularly vulnerable to perceptions of mental health stigma is supported in the literature. Results from multiple studies of college students reveal beliefs that stigma is associated with not accessing mental health treatment and individuals think less of those who receive treatment (Eisenberg et al., 2009; Rosenthal \& Wilson, 2016). The National Alliance on Mental Illness' (NAMI; 2012) survey of college student mental health found $64 \%$ of students who dropped out within the prior five years reported reasons related to a mental health issue. They concluded 50\% of students did not disclose their mental health condition to their college.

The experience of a negative campus climate has several implications for college students' mental health. For instance, Byrd and McKinney's (2012) study using secondary data from the 2006 Student Development survey reported campus climate had a significant relationship with college students' overall mental health. Specifically, students who had negative experiences with campus climate were more likely to report worse mental health. Negative perceptions of campus climate are also associated with college students' help-seeking behavior. Chen et al. (2016) found perceptions of campus climate influence students' personal beliefs about mental health services. Moreover, college students 
are more likely to access supports and services for suicidal ideation if they feel connected to their campus (Samuolis et al., 2017).

As campus counseling centers continue to implement services to address the increase of mental health issues on their campuses, it is important to consider the utility of those services. Satisfaction is a common measurement used to determine the quality of counseling services (Steenbarger \& Smith, 1996), and is considered key to quality care (Stamboglis \& Jacobs, 2020). It is an indicator of clients' perceptions of counseling services, particularly their usefulness and convenience. Greater satisfaction with counseling services has also been associated with clients' perceptions of counselor cultural competence (Constantine, 2002; Fuertes \& Brobst, 2002), counselor interpersonal qualities (Heppner \& Heesacker, 1983; McNeill et al., 1987), and prompt services (Blau et al., 2015).

\section{Present Study}

To our knowledge, most prior research has not distinguished between students with histories of mental health conditions and those encountering their first onset of symptoms when examining perceptions of campus experiences and service utilization (see Constantine, 2002; Hyun et al., 2006; Winterrowd et al., 2016). What remains unclear is whether pre-existing mental health conditions or symptoms influence help-seeking once students enter the college environment. Given the age and typical onset of mental health conditions, it is important to consider both the perspectives of students with histories of mental health conditions and those experiencing their first onset of symptoms as they relate to climate and service utilization. According to Hartrey et al. (2017),

students who experience a first episode of mental illness are unlike many other disability groups in higher education because they do not have a lived experience of disability since birth or childhood nor do they have past experience of utilizing and navigating support systems in education to act as points of reference. (p. 42)

It is also important to understand the experiences of students in crisis given they are a higher risk group, where the consequences of a lack of effective intervention can be catastrophic. Accordingly, the purpose of the current study was to understand how perceptions of stigma, campus climate, and satisfaction with services differed among college students with and without histories of mental health conditions. A secondary purpose was to determine whether these perceptions also differed among college students with and without reports of self-injurious behavior, suicidal ideation, or suicide attempt within the last year. Accordingly, the present study examined the following research questions:

1. Are students' perceptions of stigma, campus climate, and satisfaction with counseling services similar or different for students with and without a history of mental health conditions?

2. Are students' perceptions of stigma, campus climate, and satisfaction with counseling services similar or different for students with and without report of selfinjurious behavior, suicidal ideation, or suicide at- tempt within the last year?

\section{Methods}

\section{Sample}

Data were derived from the Healthy Minds (HM) database, which is collected from a web-based survey used to measure mental health and service use among college students. The present study used data collected from the 2015-2016 academic year with a sample comprised of 23 academic institutions. Institutions elect to enroll in the nationwide study. The response rate for the survey was $27 \%$, with $\mathrm{N}=34,299$ as the total number of students in the database. Researchers for Healthy Minds controlled for size of enrollment at each institution by randomly sampling 4,000 students from each school. The sample selected for the present study includes only students who provided data based on our questions of interest. Sample demographics for each of the three study variables (i.e., satisfaction with campus counseling, campus climate, and stigma) are shown in $\underline{\mathrm{Ta}}-$ bles 1-3.

\section{Measures}

The HM questionnaire is comprised of three standard modules (demographics, mental health status, and mental health service utilization and help-seeking) administered to all 23 institutions. There are 11 elective modules that institutions may choose, and schools typically choose to participate in two of the elective modules. We operationalized constructs of interest using items from the standard and elective modules. The sample for each outcome variable of interest differs as indicated, because institutions select which modules to present to students. Therefore, respondents did not answer all items on the survey. The following is a description of each operationalized variable, as well as the total number of respondents based on reporting from the standard and elective modules.

\section{Stigma Regarding Mental Health $(n=16,980)$}

This variable was created to approximate individuals' perception of social and individual stigma related to mental health. Two questions were selected from the mental health service utilization and help-seeking module to represent this scale; both were rated on a 6-point Likert scale ranging from strongly agree to strongly disagree: "Most people think less of a person who has received mental health treatment", and "I would think less of a person who has received mental health treatment". Items were recoded so that higher scores indicated greater perception of stigma, and responses were summed to create this variable.

\section{Campus Climate Towards Mental Health $(n=4,752)$}

The following items from the optional campus climate module were used to create a scale to approximate this variable of interest: "My school has a campus that looks out for each other", "Mental and emotional well-being are a priority", "Campus climate encourages free and open discussion of mental health", "Administration listens to concerns of student health and wellness", and "Campus environment 
negatively impacts student mental and emotional health". All items were presented as part of a 6-point Likert scale ranging from strongly agree to strongly disagree. Items were reversed scored as necessary so that a higher score would represent a more positive campus climate related to mental health. Item scores were summed to create the scale.

\section{Satisfaction With Campus Mental Health Services (n $=2,952$ )}

This scale was created to represent the outcome measure of satisfaction with campus mental health services. Items were drawn from the standard module of mental health service utilization and help-seeking. Students were asked to indicate satisfaction (6-point Likert scale ranging from very dissatisfied to very satisfied) with their experiences within the last 12 months at their college or university counseling center on the following points: convenience of hours, the location, quality of therapists or counselors, respect for privacy concerns, and ability to schedule appointments without long delays. Items were coded so that higher scores represented greater satisfaction, and scores were summed for a total satisfaction indicator.

\section{Procedures}

Independent groups t-tests were conducted to answer the following research questions: (a) Are students' perceptions of campus climate, stigma, and satisfaction with counseling services similar or different for students with and without a history of mental health diagnoses? (b) Are students' perceptions of campus climate, stigma, and satisfaction with counseling services similar or different for students with and without report self-injurious behavior, suicidal ideation, or suicide attempt within the last year?

\section{Grouping Variables}

Two "grouping variables" were created to help us determine differences between students.

History of Mental Health Diagnosis. This variable was created to identify students who reported a history of a mental health diagnosis. A series of questions in the standard module pertain to current and past mental health diagnosis. If a student indicated they were ever diagnosed with one of the following, they were coded as a "yes" for history of mental health diagnosis: depression, anxiety, eating disorder, psychosis, personality disorder, or substance abuse disorder.

Self-Injury, Suicide Ideations, and Suicide Attempts. This variable was created to identify students who reported any instances of self-injury, thoughts, plans, or attempts of suicide in the past year. If a student indicated "yes" to any of the following in the past year, they were coded as a "yes" for self-injury, suicide ideations, and suicide attempts: had suicidal thoughts, made a plan, or attempted suicide, or using one of the following methods to hurt themselves on purpose but not kill themselves (i.e., burned, punched or banged, scratched, pulled own hair, bit, interfered with wound healing, carved words or symbols into skin, rubbed sharp objects into skin, punched or banged self with an ob-
Table 1. Satisfaction With Campus Counseling: Sample Demographics $(n=2,952)$

\begin{tabular}{|c|c|}
\hline Variable & $\mathrm{n}(\%)$ \\
\hline \multicolumn{2}{|l|}{ Gender Identity } \\
\hline Male & $685(23.2)$ \\
\hline Female & $2,183(74.0)$ \\
\hline Other & $81(2.7)$ \\
\hline \multicolumn{2}{|l|}{ Race or Ethnicity } \\
\hline White & $2,392(81.0)$ \\
\hline African-American & $168(5.7)$ \\
\hline Latinx & $287(9.7)$ \\
\hline Asian-American & $346(11.7)$ \\
\hline $\mathrm{Al} / \mathrm{NA} / \mathrm{AN}^{1}$ & $55(1.9)$ \\
\hline Arab-American & 49 (1.7) \\
\hline Other & $145(4.9)$ \\
\hline \multicolumn{2}{|l|}{ Year in Degree Program } \\
\hline 1st year & $660(22.4)$ \\
\hline 2nd year & $844(28.6)$ \\
\hline 3rd year & $687(23.3)$ \\
\hline 4 th year & $612(20.7)$ \\
\hline 5 th year or higher & $139(4.8)$ \\
\hline \multicolumn{2}{|c|}{ History of Mental Health Diagnosis } \\
\hline Reports History & $1,841(62.4)$ \\
\hline Reports No History & $1,111(37.6)$ \\
\hline \multicolumn{2}{|c|}{ Reports SIB/SI/SA 2 in Past Year } \\
\hline Yes & $1,219(41.3)$ \\
\hline \multirow[t]{2}{*}{ No } & $1,733(58.7)$ \\
\hline & $M(S D)$ \\
\hline Age & $21.9(4.25)$ \\
\hline \multicolumn{2}{|c|}{${ }^{1}$ American Indian/Native American/Alaska Native } \\
\hline Self-injurious behavior/Suicidal ide & \\
\hline
\end{tabular}

ject).

\section{Results}

To address the first research question, the perception of campus climate, stigma, and satisfaction with counseling variables were entered into a series of independent samples t-tests. For two of the three variables (i.e., campus climate and stigma), the homogeneity of variances assumption was violated; therefore, the correction was applied. Significant mean differences were found between groups on all three variables. Students with a history of mental health diagnosis had a less positive perception of the campus climate $(\mathrm{t}(2978.964)=7.407, \mathrm{p}<.001)$, higher perception of stigma associated with mental health $(\mathrm{t}(9894.518)=-3.080, \mathrm{p}=$ .002 ), and lower satisfaction with counseling than students who did not report a history of mental health diagnosis $(t(2950)=3.458, p=.001)$. Full results are available in Table 4.

To address the second research question, we entered the 
Table 4. Means and Group Differences in Satisfaction With Counseling, Campus Climate, and Stigma by History of Mental Health Diagnosis

\begin{tabular}{|c|c|c|c|c|}
\hline \multirow[t]{2}{*}{ Variable } & \multicolumn{2}{|c|}{ Students Reporting MH } & \multicolumn{2}{|c|}{ Students Not Reporting MH } \\
\hline & \multicolumn{2}{|c|}{$M(S D)$} & \multicolumn{2}{|c|}{$M(S D)$} \\
\hline Satisfaction with Counseling & \multicolumn{2}{|c|}{$23.95(4.44)$} & \multicolumn{2}{|c|}{$24.52(4.32)$} \\
\hline Campus Climate & \multicolumn{2}{|c|}{$15.00(3.20)$} & \multicolumn{2}{|c|}{$15.69(2.74)$} \\
\hline \multirow[t]{2}{*}{ Stigma } & \multicolumn{2}{|c|}{$.21(1.72)$} & \multicolumn{2}{|c|}{$9.13(1.68)$} \\
\hline & df & $\mathrm{t}$ & $95 \% \mathrm{Cl}$ & Sig. \\
\hline Satisfaction with Counseling & 2950 & 3.458 & $(.25, .90)$ & .001 \\
\hline Campus Climate & 2978.964 & 7.407 & $(.50, .87)$ & $<.001$ \\
\hline Stigma & 9894.518 & -3.080 & $(-.14,-.03)$ & .002 \\
\hline
\end{tabular}

Table 5. Means and Group Differences in Satisfaction With Counseling, Campus Climate, and Stigma by SelfInjurious Behavior, Suicidal Ideation, and Suicide Attempt Status

\begin{tabular}{|c|c|c|c|c|}
\hline \multirow[t]{2}{*}{ Variable } & \multicolumn{2}{|c|}{ Reporting SIB/SI/SA ${ }^{1}$} & \multicolumn{2}{|c|}{ Not Reporting SIB/SI/SA ${ }^{1}$} \\
\hline & \multicolumn{2}{|c|}{$M(S D)$} & \multicolumn{2}{|c|}{$M(S D)$} \\
\hline Satisfaction with Counseling & \multicolumn{2}{|c|}{$23.64(4.54)$} & \multicolumn{2}{|c|}{$24.54(4.26)$} \\
\hline Campus Climate & \multicolumn{2}{|c|}{$14.93(2.83)$} & \multicolumn{2}{|c|}{$15.62(2.83)$} \\
\hline \multirow[t]{2}{*}{ Stigma } & \multicolumn{2}{|c|}{$9.37(1.79)$} & \multicolumn{2}{|c|}{$9.09(1.66)$} \\
\hline & df & $\mathrm{t}$ & $95 \% \mathrm{Cl}$ & Sig. \\
\hline Satisfaction with Counseling & 2517.731 & .473 & $(.58,1.23)$ & $<.001$ \\
\hline Campus Climate & 1846.827 & 6.739 & $(.49, .90)$ & $<.001$ \\
\hline Stigma & 5619.599 & -8.431 & $(-.34,-.21)$ & $<.001$ \\
\hline
\end{tabular}

${ }^{1}$ Self-injurious behavior/Suicidal ideation/Suicide attempt

perception of campus climate, stigma, and satisfaction with counseling variables into a series of independent samples ttests, using the correction when the homogeneity of variance assumption was violated. Significant mean differences were detected between groups on all three variables. Students who reported self-injurious behavior, suicidal ideation, or a suicide attempt in the past year had a less positive perception of the campus climate $(\mathrm{t}(1846.827)=$ $6.739, \mathrm{p}<.001)$, higher perception of stigma associated with mental health $(\mathrm{t}(5619.599)=-8.431, \mathrm{p}<.001)$, and lower satisfaction with counseling than students who did not report self-injurious behavior, suicidal ideation, or a suicide attempt in the past year $(\mathrm{t}(2517.731)=5.473, \mathrm{p}<.001)$. Full results for this analysis are available in Table 5.

\section{Discussion}

The present study examined perceptions of campus climate, stigma, and satisfaction with counseling services among college students using data from the 2015-2016 Healthy Minds (HM) questionnaire. Results suggested students with histories of mental health diagnoses have fewer positive perceptions of campus climate, higher perceptions of stigma, and lower satisfaction with counseling services. Furthermore, students who reported self-injurious behavior, suicidal ideation, or a suicide attempt within the last year had similar perceptions. Findings from the present study have implications for both students with mental health histories and college campuses, including training programs for counselors, student disability resource (SDR) offices, and student affairs personnel. First, college students with greater need for intervention generally report having higher perceptions of mental health stigma and have more negative perceptions of campus climate. This is concerning given individuals with mental health conditions have an increased risk of college dropout compared to the general student population (Salzer, 2011). Although college students are increasingly seeking mental health services (Gallagher, 2014), findings showed that current study participants generally perceived their mental health issues are not fully understood or supported by the larger campus community.

To address this issue, Chen et al. (2016) and Samuolis et al. (2017) suggested the promotion of mental health outreach, coupled with policies and programs that target perceptions of campus climate, can help increase students' attitudes towards mental health issues, thus increasing their help-seeking behaviors. SDR offices are a natural fit for these initiatives, and are often already at the leading edge of outreach and policy concerning disability issues, including campus climate and stigma. Student voices should be added to discussions with administrators, faculty, and staff to share a larger role in the development and implementation of campus initiatives, particularly to inform first-per- 
son narratives of the role of mental health in academic success and persistence, and how campus climate impacts students. Their experiences can be used as vital resources to inform the implementation of mental health initiatives on campus. Hurtado et al. (1998) also suggested efforts, such as evaluation initiatives to understand student perceptions of climate, as a necessary step to promote inclusivity across college campuses.

Second, our findings on satisfaction add to knowledge gained in previous studies that found college students are generally satisfied with their university's counseling services (Winterrowd et al., 2016). Students with pre-existing mental health conditions in this study were less satisfied than those who had no prior mental health history. This is an important distinction to make when examining perceptions, considering college students with mental health conditions have different campus experiences compared to the general student population (Salzer, 2011). Moreover, our findings are concerning in light of the increasing population of students in crisis reported by campus counseling center directors (Reetz et al., 2016). Satisfaction with services has shown to be highly correlated with other mental health outcomes, such as quality of life (Blenkiron \& Hammill, 2003) and service dropout (Mueller \& Pekarik, 2000), and thus is an important consideration for supporting college students with mental health conditions.

To address this issue, we recommend tailoring mental health services and other supports to meet the unique needs of college students. Partnerships between campus counseling centers and disability service offices are vital. This is especially true given students with mental health conditions are less likely than other students with disabilities to be registered for disability services (O’Shea \& Kaplan, 2018), and as a result are less likely to receive additional support from instructors, even though most agree it would be helpful (Lightner et al., 2012). Campus counseling centers should also conduct satisfaction assessments among their student clientele to better understand their overall experiences with the counseling process, including students with complex needs and high service utilization, such as the individuals in our sample. Winterrowd et al. (2016) suggested doing so can help ensure services are aligned with the mission of the academic institution and demonstrate funding needs to support campus counseling centers. Other recommendations for improving the counseling experience are aligned with Maffini and Toth's (2017) suggestions for conducting evaluation surveys, as they can be used to inform the effectiveness of interventions and develop programming.

With the onset of most mental health conditions peaking during late adolescence and early adulthood (Pedrelli et al., 2015), it is apparent some college students with mental health conditions go undiagnosed, or are newly diagnosed during their time on campus, with limited understanding of their condition and its implications. They may not know of, or identify with, the disability services office, and further, may be reluctant to disclose due to stigma associated with mental health and the lack of support available to meet their specific needs. This point is underscored by a statement from a student in a NAMI (2012) study of college students and mental health:
Table 2. Campus Climate: Sample Demographics $(\mathrm{n}=$ 4,752)

\begin{tabular}{|c|c|}
\hline Variable & $n(\%)$ \\
\hline \multicolumn{2}{|l|}{ Gender Identity } \\
\hline Male & $1,580(33.3)$ \\
\hline Female & $3,086(65.0)$ \\
\hline Other & $86(1.7)$ \\
\hline \multicolumn{2}{|l|}{ Race or Ethnicity } \\
\hline White & $992(81.0)$ \\
\hline African-American & $235(4.9)$ \\
\hline Latinx & $578(12.2)$ \\
\hline Asian-American & $992(20.9)$ \\
\hline $\mathrm{Al} / \mathrm{NA} / \mathrm{AN}^{1}$ & $65(1.4)$ \\
\hline Arab-American & $124(2.6)$ \\
\hline Other & $275(5.8)$ \\
\hline \multicolumn{2}{|l|}{ Year in Degree Program } \\
\hline 1st year & $1,600(33.9)$ \\
\hline 2nd year & $1,267(26.8)$ \\
\hline 3rd year & $892(18.9)$ \\
\hline 4th year & $746(15.7)$ \\
\hline 5 th year or higher & $217(4.5)$ \\
\hline \multicolumn{2}{|c|}{ History of Mental Health Diagnosis } \\
\hline Reports History & $1,660(34.9)$ \\
\hline Reports No History & $3,092(65.1)$ \\
\hline \multicolumn{2}{|c|}{ Reports SIB/SI/SA ${ }^{2}$ in Past Year } \\
\hline Yes & $1,175(24.7)$ \\
\hline \multirow[t]{2}{*}{ No } & $3,577(75.3)$ \\
\hline & $M(S D)$ \\
\hline Age & $23.3(5.63)$ \\
\hline
\end{tabular}

${ }^{1}$ American Indian/Native American/Alaska Native

${ }^{2}$ Self-injurious behavior/Suicidal ideation/Suicide attempt

I think colleges should pay attention to the fact that many more students need mental health services than who actually access them. Some of the students most affected or most at risk for mental health conditions are the hardest to reach because they are secluded in their rooms. (p. 4)

We support Collins and Mowbray's (2005) call for a collaborative effort between SDR offices and campus counseling centers to meet the needs of students with mental health conditions. This requires both providers to be aware of, and educated on, their respective services, and how they are used to promote students' academic success. This is further extended to considerations for a two-way referral system to ensure students are educated on available campus resources to meet their mental health needs and mitigate gaps in service provision. In doing so, the need for rehabilitation and clinical mental health counselors to be aware of each other's respective roles and services within their fields is critical. According to the 2016 Standards for the Council for the Accreditation of Counseling and Related Programs 
(CACREP; 2015), counselor education programs must address the history and philosophy of counseling specialty areas and the roles of interdisciplinary work in courses addressing professional counseling orientation and ethical practice (see sections F.1.a and F.1.c). This is especially important considering rehabilitation counseling programs may be housed in other departments, such as health sciences. As such, rehabilitation counseling students may not share core courses with counseling students in other emphasis areas; therefore, such information may be overlooked in the curriculum.

Results of the study, while interesting, should be considered within the context of several limitations. First, use of self-report data is limited to respondents' perceptions. It is possible that students' perceptions of stigma, campus climate, and satisfaction with services are the result of other issues unrelated to their mental health. Second, the majority of respondents identified as being White and our sample was overrepresented by women. As such, results from the present study should be interpreted with limitations in mind for cross-cultural generalizations. Future research should address this gap given perceptions of stigma, campus climate, and satisfaction with services are likely related to culture and identity. Third, the sample sizes used in the present study were large; future research should address limitations of effect size when using large data sets. Fourth, the present study used data from the 2015-2016 sample. Thus, the impact on college student mental health related to the COVID-19 pandemic, political climate, and ongoing concerns for social injustice were not assessed. Future research should examine current data with these considerations in mind. Lastly, although data used from the HM questionnaire has been distributed to various universities and college campuses, results should be interpreted with the reader's current academic institution in mind.

\section{Conclusion}

Addressing mental health concerns among college students is a shared initiative across campus communities. Although mental health conditions peak during young adulthood, many students are already attending college with histories of mental health issues. As such, students require a campus environment that is understanding of and supportive to their mental health needs. Our study found college students with histories of mental health conditions had fewer positive perceptions of stigma, campus climate, and satisfaction with their campus counseling experiences. Similar results were also found across students at higher risks for mental health crises. These findings suggest students with mental health histories are most vulnerable to nega-
Table 3. Stigma: Sample Demographics $(n=16,980)$

\begin{tabular}{|c|c|}
\hline Variable & $\mathrm{n}(\%)$ \\
\hline \multicolumn{2}{|l|}{ Gender Identity } \\
\hline Male & $6,042(35.6)$ \\
\hline Female & $10,720(63.2)$ \\
\hline Other & $203(1.1)$ \\
\hline \multicolumn{2}{|l|}{ Race or Ethnicity } \\
\hline White & $13,412(81.0)$ \\
\hline African-American & 635 (3.7) \\
\hline Latinx & $1,320(7.8)$ \\
\hline Asian-American & 2,703 (15.9) \\
\hline $\mathrm{Al} / \mathrm{NA} / \mathrm{AN}^{1}$ & $243(1.4)$ \\
\hline Arab-American & $281(1.7)$ \\
\hline Other & $618(3.6)$ \\
\hline \multicolumn{2}{|l|}{ Year in Degree Program } \\
\hline 1st year & $5,007(29.7)$ \\
\hline 2nd year & $4,288(25.3)$ \\
\hline 3rd year & $3,507(20.8)$ \\
\hline 4th year & $3,072(18.2)$ \\
\hline 5 th year or higher & $998(5.9)$ \\
\hline \multicolumn{2}{|c|}{ History of Mental Health Diagnosis } \\
\hline Reports History & $5,250(30.9)$ \\
\hline Reports No History & $11,730(69.1)$ \\
\hline \multicolumn{2}{|c|}{ Reports SIB/SI/SA ${ }^{2}$ in Past Year } \\
\hline Yes & $3,711(21.9)$ \\
\hline \multirow[t]{2}{*}{ No } & $13,269(78.1)$ \\
\hline & $M(S D)$ \\
\hline Age & $22.57(5.22)$ \\
\hline American Indian/Native American/ & \\
\hline
\end{tabular}

tive campus experiences, signifying campus initiatives may not be fully addressing students' unique needs. Regularly assessing campus climate is a necessary first step that universities and colleges must take in order to promote more inclusive environments for all students. Campuses must also address stigma surrounding mental health and promote access to underutilized campus resources, such as SDR offices. Finally, campus counseling centers and SDR offices should collaborate and regularly evaluate students' satisfaction with their services to make necessary changes that could improve students' overall experiences and outcomes. 


\section{REFERENCES}

Abreu, M., Hillier, A., Frye, A., \& Goldstein, G. (2016). Student experiences utilizing disability support services in a university setting. College Student Journal, 50(3), 323-328.

Blau, G., DiMino, J., Sheridan, N., Stein, A., Casper, S., Chessler, M., \& Beverly, C. (2015). Wait time for counseling affecting perceived stigma and attitude toward the university. College Student Journal, 49(2), 280-290.

Blenkiron, P., \& Hammill, C. A. (2003). What determines patients' satisfaction with their mental health care and quality of life? Postgraduate Medical Journal, 79(932), 337-340. https://doi.org/10.1136/pmj.79.93 $\underline{2.337}$

Byrd, D. R., \& McKinney, K. J. (2012). Individual, interpersonal, and institutional level factors associated with the mental health of college students. Journal of American College Health, 60(3), 185-193. htt ps://doi.org/10.1080/07448481.2011.584334

Campbell, T., \& Wescott, J. (2019). Profile of undergraduate students: Attendance, distance and remedial education, degree program and field of study, demographics, financial aid, financial literacy, employment, and military status: 2015-16 (NCES 2019-467). U.S. Department of Education. National Center for Education Statistics. https://nces.ed.gov/p ubs2019/2019467.pdf

Center for Collegiate Mental Health. (2019). 2018 annual report. https://ccmh.psu.edu/assets/docs/2018-Annua 1-Report-9.27.19-FINAL.pdf

Center for Collegiate Mental Health. (2021). 2020 Annual report. https://ccmh.psu.edu/assets/docs/202 0\%20CCMH\%20Annual\%20Report.pdf

Chen, J. I., Romero, G. D., \& Karver, M. S. (2016). The relationship of perceived campus culture to mental health help-seeking intentions. Journal of Counseling Psychology, 63(6), 677-684. https://doi.org/10.1037/co u0000095

Collins, M. E., \& Mowbray, C. T. (2005). Higher education and psychiatric disabilities: National survey of campus disability services. American Journal of Orthopsychiatry, 75(2), 304-315. https://doi.org/1 $\underline{0.1037 / 0002-9432.75 .2 .304}$

Constantine, M. G. (2002). Predictors of satisfaction with counseling: Racial and ethnic minority clients' attitudes toward counseling and ratings of their counselors' general and multicultural counseling competence. Journal of Counseling Psychology, 49(2), 255-263. https://doi.org/10.1037//0022.-0167.49.2.25 $\underline{5}$

Corrigan, P. (2004). How stigma interferes with mental health care. American Psychologist, 59(7), 614-625. ht tps://doi.org/10.1037/0003-066x.59.7.614

Council for the Accreditation of Counseling and Related Programs. (2015). 2016 CACREP standards. http://ww w.cacrep.org/wp-content/uploads/2017/08/2016-Stan dards-with-citations.pdf
Eisenberg, D., Golberstein, E., \& Hunt, J. B. (2009). Mental health and academic success in college. The B.E. Journal of Economic Analysis \& Policy, 9(1), 1-37. https://doi.org/10.2202/1935-1682.2191

Fuertes, J. N., \& Brobst, K. (2002). Clients' ratings of counselor multicultural competency. Cultural Diversity and Ethnic Minority Psychology, 8(3), 214-223. https://doi.org/10.1037/1099-9809.8.3.214

Gallagher, R. P. (2014). National survey of counseling directors. The International Association of Counseling Services. http://d-scholarship.pitt.edu/28178/1/surve y_2014.pdf

Hartley, M. T. (2010). Increasing resilience: Strategies for reducing dropout rates for college students with psychiatric disabilities. American Journal of Psychiatric Rehabilitation, 13(4), 295-315. https://doi.org/10.108 $\underline{0 / 15487768.2010 .523372}$

Hartrey, L., Denieffe, S., \& Wells, J. S. G. (2017). A systematic review of barriers and supports to the participation of students with mental health difficulties in higher education. Mental Health \& Prevention, 6, 26-43. https://doi.org/10.1016/j.mhp.20 $\underline{17.03 .002}$

Heppner, P. P., \& Heesacker, M. (1983). Perceived therapist characteristics, client expectations, and client satisfaction with counseling. Journal of Counseling Psychology, 30(1), 31-39. https://doi.org/1 0.1037/0022-0167.30.1.31

Hurtado, S., Carter, D. F., \& Kardia, D. (1998). The climate for diversity: Key issues for institutional selfstudy. New Directions for Institutional Research, 1998(98), 53-63. https://doi.org/10.1002/ir.9804

Hyun, J. K., Quinn, B. C., Madon, T., \& Lustig, S. (2006). Graduate student mental health: Needs assessment and utilization of counseling services. Journal of College Student Development, 47(3), 247-266. https://d oi.org/10.1353/csd.2006.0030

Leahy, M. J., Muenzen, P., Saunders, J., \& Strauser, D. (2008). Essential knowledge domains underlying effective rehabilitation counseling practice. Journal of Applied Rehabilitation Counseling, 39(4), 28-38. http s://doi.org/10.1891/0047-2220.39.4.28

Lightner, K. L., Kipps-Vaughan, D., Schulte, T., \& Trice, A. D. (2012). Reasons university students with a learning disability wait to seek disability services. Journal of Postsecondary Education and Disability, 25(2), 145-159. https://files.eric.ed.gov/fulltext/EJ994 283.pdf

Maffini, C. S., \& Toth, P. L. (2017). Quality improvement in university counseling centers. Journal of College Student Psychotherapy, 31(1), 43-58. https://doi.org/1 $0.1080 / 87568225.2016 .1254000$

Martinez, A., \& Nguyen, S. (2020). The impact of COVID-19 on college student well-being. Healthy Minds Network and The American College Health Association. https://www.acha.org/documents/ncha/ Healthy-Minds NCHA COVID-19_Survey_Report.pdf 
Maxwell, V. (2014). Accommodations for students with psychiatric disabilities. Psychology Today. https://ww w.psychologytoday.com/us/blog/crazy-life/201402/acc ommodations-students-psychiatric-disabilities

McNeill, B. W., May, R. J., \& Lee, V. E. (1987). Perceptions of therapist source characteristics by premature and successful terminators. Journal of Counseling Psychology, 34(1), 86-89. https://doi.org/1 0.1037/0022-0167.34.1.86

Michaels, P. J., Buchholz, B., Corrigan, P. W., Abelson, S., \& Kanodia, N. (2015). Mental health priorities: Stigma elimination and community advocacy in college settings. Journal of College Student Development, 56(8), 872-875. https://doi.org/10.1353/ csd.2015.0088

Mojtabai, R., Olfson, M., Sampson, N. A., Jin, R., Druss, B., Wang, P. S., Wells, K. B., Pincus, H. A., \& Kessler, R. C. (2011). Barriers to mental health treatment: Results from the national comorbidity survey replication. Psychological Medicine, 41(8), 1751-1761. https://doi.org/10.1017/s0033291710002291

Mueller, M., \& Pekarik, G. (2000). Treatment duration prediction: Client accuracy and its relationship to dropout, outcome, and satisfaction. Psychotherapy, 37(2), 117-123. https://doi.org/10.1037/h0087701

Murphy, M. C., \& Martin, T. L. (2004). Introducing a team-based clinical intake system at a university counseling center: A good method for handling client demand. Journal of College Student Psychotherapy, 19(2), 3-12. https://doi.org/10.1300/J035v19n02-02

National Alliance on Mental Illness. (2012). College students speak: A survey report on mental health. http s://www.nami.org/Support-Education/Publications-R eports/Survey-Reports/College-Students-Speak_A-Su rvey-Report-on-Mental-H

National Council on Disability. (2017). Mental health on college campuses: Investments, accommodations, needed to address student needs. https://ncd.gov/sites/ default/files/NCD_Mental_Health_Report_508_0.pdf

O’Shea, A., \& Kaplan, A. (2018). Disability identity and use of services among college students with psychiatric disabilities. Qualitative Psychology, 5(3), 358-379. https://doi.org/10.1037/qup0000099

Pedrelli, P., Nyer, M., Yeung, A., Zulauf, C., \& Wilens, T. (2015). College students: Mental health problems and treatment considerations. Academic Psychiatry, 39(5), 503-511. https://doi.org/10.1007/s40596-014-0205-9

Reetz, D., Bershad, C., LeViness, P., \& Whitlock, M. (2016). The Association for University and College Counseling Center Directors annual survey. https://tauc ccd.memberclicks.net/assets/documents/aucccd\%202 016\%20monograph\%20- \%20public.pdf

Ringelsen, H., Ryder-Burge, A., Ellison, M. L., Biebel, K., \& Alikhan, S. (2015). Feasability study for demonstration of supported education to promote educational attainment and employment among individuals with serious mental illness: Final report. The Office of the Assistant Secretary for Planning and Evaluation. https://aspe.hhs.gov/system/files/pdf/183 661/smiSEd.pdf
Rosenthal, B. S., \& Wilson, W. C. (2016). Psychosocial dynamics of college students' use of mental health services. Journal of College Counseling, 19(3), 194-204. https://doi.org/10.1002/jocc.12043

Salzer, M. S. (2011). A comparative study of campus experiences of college students with mental illnesses versus a general college sample. Journal of American College Health, 60(1), 1-7. https://doi.org/10.1080/074 48481.2011.552537

Samuolis, J., Griffin, K., Mason, M., \& Dekraker, N. (2017). Connectedness to campus and likelihood of help-seeking for suicidality among college women. Journal of College Student Psychotherapy, 31(3), 238-246. https://doi.org/10.1080/87568225.2017.1312 $\underline{76}$

Schwartz, V. (2017). Suicide among college students: Risk and approaches to prevention and management. Psychiatric Annals, 47(8), 406-411. https://doi.org/1 0.3928/00485713-20170706-01

Stamboglis, N., \& Jacobs, R. (2020). Factors associated with patient satisfaction of community mental health services: A multilevel approach. Community Mental Health Journal, 56(1), 50-64. https://doi.org/10.1007/s 10597-019-0049-X

Steenbarger, B. N., \& Smith, H. B. (1996). Assessing the quality of counseling services: Developing accountable helping systems. Journal of Counseling and Development, 75(2), 145-150. https://doi.org/10.1 002/j.1556-6676.1996.tb02325.x

Tompkins, T. L., \& Witt, J. (2009). The short-term effectiveness of a suicide prevention gatekeeper training program in a college setting with residence life advisers. Journal of Primary Prevention, 30(2), 131-149. https://doi.org/10.1007/s10935-009-0171-2

Turk, J. M., Soler, M. C., \& Ramos, A. M. (2020). College and university presidents respond to COVID-19: 2020 fall term survey. American Council on Education. http s://www.acenet.edu/Documents/Presidents-RespondCOVID19-Fall2020.pdf

Vogel, D. L., Wade, N. G., \& Ascheman, P. L. (2009). Measuring perceptions of stigmatization by others for seeking psychological help: Reliability and validity of a new stigma scale with college students. Journal of Counseling Psychology, 56(2), 301-308. https://doi.or g/10.1037/a0014903

Walther, W. A., Abelson, S., \& Malmon, A. (2014). Active minds: Creating peer-to-peer mental health awareness. Journal of College Student Psychotherapy, 28(1), 12-22. https://doi.org/10.1080/87568225.201 $\underline{4.854673}$

Winterrowd, E., Prinski, S. J., Achter, J., \& Abhold, J. J. (2016). Correlates of satisfaction, intrapersonal learning, and academic outcomes at counseling centers in a university system. College Student Journal, 50(2), 288-301.

Xiao, H., Carney, D. M., Youn, S. J., Janis, R. A., Castonguay, L. G., Hayes, J. A., \& Locke, B. D. (2017). Are we in crisis? National mental health and treatment trends in college counseling centers. Psychological Services, 14(4), 407-415. https://doi.org/ $\underline{10.1037 / \text { ser0000130 }}$ 
Yamaguchi, S., Mino, Y., \& Uddin, S. (2011). Strategies and future attempts to reduce stigmatization and increase awareness of mental health problems among young people: A narrative review of educational interventions. Psychiatry and Clinical Neurosciences, 65(5), 405-415. https://doi.org/10.1111/j.1440-1819.2 01 